\title{
Mechanical Properties of Dissimilar Friction Stir Welded Joints between AA7075-O and AA6061-O Alloys
}

\author{
Nahit Öztoprak*, H. Tarık Serindağ, Ç. Emine Yeni, B. Gören Kıral \\ Dokuz Eylul University \\ Dokuz Eylul University, Mechanical Engineering Department, 35397, Izmir, Turkey \\ nahit.oztoprak@deu.edu.tr; tarik.serindag@deu.edu.tr; cinar.yeni@deu.edu.tr; binnur.goren@deu.edu.tr
}

\section{Extended Abstract}

Friction stir welding (FSW) is a new solid-state joining technique that was developed in 1991 by The Welding Institute (TWI) of UK. In particular, this process is utilized for welding high-strength metallic materials such as aluminum alloys, magnesium, copper and metal matrix composites (MMCs) that are hard to weld by traditional welding methods. In FSW process, the frictional heating is generated between the non-consumable tool and the workpiece. As a result of the heating, the workpiece undergoes intensive plastic flow at an elevated temperature that is under the melting point of the material. Attendantly, the plastic deformation introduces grain refinement owing to the dynamic recrystallization of the grains at the weld zone. There are many advantages of FSW process by comparison with conventional fusion welding technology. No additive materials, cover gas or flux is used in the process and this makes FSW technology a strong candidate for joining of the aforementioned materials. In addition, several types of joints such as butt and $\mathrm{T}$ butt joints or fillet joints can be simply welded by this significant technology [1].

AA7075 alloy (Al-Zn-Mg-Cu alloy), which is one of the strongest aluminum alloys, is precipitation hardened wrought material commonly used in aircraft parts, gears and shafts, missile parts, aerospace and defence applications [2]. It has gathered wide acceptance in many structural applications due to its high strength to weight ratio, good resistance to corrosion and natural ageing characteristics [3,4]. In addition, AA6061 alloy (Al-Mg-Si alloy) belongs to a significant class of medium strength aluminum alloys widely used in aircraft applications, marine frames and storage tanks [5]. However, both alloys suffer from degraded mechanical properties especially in the heat affected zone (HAZ) subsequent to conventional fusion welding techniques [5,6]. Therefore, FSW is considered as an ideal candidate to join these materials which are known as non-weldable alloys by fusion welding processes.

Joining of dissimilar monolithic metals is quite important so as to provide good mechanical performance and obtaining cost-effective joints. AA7075-O and AA6061-O alloys have common widespread applications [7]. Therefore, sound welding of these materials is a prerequisite and attractive in various applications. In this research, dissimilar welds were produced in $3.2 \mathrm{~mm}$ thick plates of AA7075-O and AA6061-O alloys by friction stir welding. The effect of welding parameters and material position on tensile strength of the joints and microhardness profiles across the welds were investigated. For this purpose, FSW was carried out with the combination of two different rotational speeds and one welding speed to obtain the effect of heat generation on the welding quality. The parameters were chosen by taking into consideration the results of preliminary experimental studies. Temperature distribution around the weld zone was also measured during the process by using a non-contact infrared thermometer and K-type thermocouple.

\section{References}

[1] R. S. Mishra and Z. Y. Ma, "Rev. of Friction stir welding and processing," Materials Science and Engineering, vol. R 50, pp. 1-78, 2005.

[2] P. Bahemmat, M. Haghpanahi, M.K.B. Givi and K.R. Seighalani, "Study on dissimilar friction stir butt welding of AA7075-O and AA2024-T4 considering the manufacturing limitation," Internatiol Journal of Advanced Manufacturing Technology, vol. 59, pp. 939-953, 2012.

[3] M. H. Shojaeefard, R. A. Behnagh, M. Akbari, M. K. B. Givi and F. Farhani, "Modelling and Pareto optimization of mechanical properties of friction stir welded AA7075/AA5083 butt joints using neural network and particle swarm algorithm," Materials and Design, vol. 44, pp. 190-198, 2013. 
[4] K. Dehghani, R. Ghorbani and A. R. Soltanipoor, "Microstructural evolution and mechanical properties during the friction stir welding of 7075-O aluminum alloy," Internatiol Journal of Advanced Manufacturing Technology, vol. 77, pp. 1671-1679, 2015.

[5] K. Elangovan, V. Balasubramanian and M. Valliappan, "Influences of tool pin profile and axial force on the formation of friction stir processing zone in AA6061 aluminum alloy," Internatiol Journal of Advanced Manufacturing Technology, vol. 38, pp. 285-295, 2008.

[6] M. Yuqing, K. Liming, L. Fencheng, L. Qiang, H. Chunping and X. Li, "Effect of tool pin eccentricity on microstructure and mechanical properties in friction stir welded 7075 aluminum alloy thick plate," Materials and Design, vol. 62, pp. 334-343, 2014.

[7] G. İpekoğlu and G. Çam, "Effects of initial temper condition and postweld heat treatment on the properties of dissimilar friction-stir-welded joints between AA7075 and AA6061 aluminum alloys," Metallurgical and Materials Transactions A, vol. 45A, pp. 3074-3087, 2014. 